\title{
CIÊNCIA, ÉTICA E SOCIEDADE: a regulação da prática científica
}

\author{
Telma de Souza Birchal
}

\begin{abstract}
Neste texto, pretendemos mostrar como, nas últimas décadas, a relação entre a ciência e a ética tornou-se central na prática científica. Questões recentes desafiam o comprometimento do conhecimento científico com uma visão objetiva das coisas e com a promoção da felicidade. Para pensar tais questões, tomamos de empréstimo o conceito de prática, tal como explicitado pelo filósofo moral escocês Alasdair MacIntyre, no intuito de compreender a relação entre as questões propriamente ligadas ao conhecimento científico e as questões ligadas à utilidade da ciência. Como conclusão, julgamos que cabe destacar uma tarefa atual para os cientistas: a de defender não só os clássicos valores intrínsecos da ciência, definidores de sua própria prática, mas também de atentar para o lugar vital que a ciência ocupa em nossa sociedade e para os seus chamados valores extrínsecos, que, na verdade, fazem parte de seu modus operandi.

PALAVRAS-CHAVE: Ciência. Ética. MacIntyre. Prática.
\end{abstract}

O fator utilidade faz a ciência pós-acadêmica responsável por suas operações diante das pessoas e instituições fora da comunidade científica. Isto é mais do que a questão de limitar a liberdade dos cientistas na busca do conhecimento 'por ele mesmo'. Isto infunde no ethos científico a ética como o mundo a conhece. A ciência pós-acadêmica, estando muito mais diretamente conectada com a sociedade em geral, tem que compartilhar seus valores e preocupações mais amplos. (Ziman, 2000)

Neste texto, pretendemos mostrar como, nas últimas décadas, a relação entre a ciência e a ética tornou-se central na prática científica. ${ }^{1}$ Um iniciante na pesquisa científica encontra hoje uma série de questões que não existiam, ou pelo menos não se colocavam com clareza, há vinte ou trinta anos atrás, tais como: a ética na pesquisa com seres humanos ou animais; o caráter útil ou nocivo dos possíveis

* Doutora em Filosofia. Professora Universidade Federal de Minas Gerais.

Av. Antônio Carlos, 6627. Pampulha. Cep: 31270-901 Belo Horizonte, MG - Brasil. tbirchal@gmail.com

${ }^{1}$ Este texto origina-se de palestra proferida no XI Congresso da Sociedade Brasileira de Toxicologia, ocorrido em Araxá, em novembro de 2010. Foi, portanto, pensado, tendo em vista um público formado em sua maioria por cientistas e estudantes da área de ciências biológicas. Agradeço a Ivan Domingues pelas sugestões que contribuíram para dar ao artigo sua forma final. desdobramentos de um conhecimento; se o conhecimento deve ou não ser objeto de propriedade (o tema das patentes ou do direito da pessoa aos tecidos de seu corpo, por exemplo).

Como ponto de partida, abordaremos duas ideias centrais a respeito da ciência e que a definiram desde sua origem na chamada Revolução Científica do século XVII: $1^{\mathrm{a}}$ - o conhecimento científico é comprometido com uma visão objetiva das coisas, obtida mediante pesquisa e crítica, o que implica ser ele desvinculado de quaisquer outros interesses e crenças; $2^{\mathrm{a}}$ - o conhecimento científico leva à promoção da felicidade do ser humano, ao redundar num maior controle e domínio da natureza, proporcionando-lhe conforto e vida boa.

Para pensar esse problema, tomamos de empréstimo o conceito de prática, tal como é explicitado pelo filósofo moral escocês Alasdair MacIntyre, no intuito de compreender a relação entre as questões propriamente ligadas ao conhecimento científico e as questões ligadas à utilidade da ciência:

Vamos entender como prática as atividades humanas colaborativas, que visam a um fim ou bem interno a elas e exigem certos padrões de exce- 
lência para serem realizadas. O leque das práticas é amplo: artes, ciências, jogos, política no sentido aristotélico, constituição e sustento da família (MacIntyre, 2001, p. 316).

As práticas definem-se por seus fins internos e têm também fins externos. Tomemos como exemplo um jogo, como o de futebol. Seu objetivo é fazer gols e, para isso, exigem-se padrões de preparo físico, agilidade e inteligência, para armar as jogadas. O fim interno do futebol é, então, ganhar a partida. Não se trata, porém, de ganhar de qualquer jeito (comprando o juiz, por exemplo), e, sim, jogando segundo as regras e desempenhando bem o papel de time. Se um time ganhou porque comprou o juiz, não podemos dizer, de verdade, que houve uma vitória, ou mesmo que houve um jogo. De tudo isso se conclui que faltar aos seus fins ou valores internos corrompe a própria prática do jogo.

Uma prática tem, também, fins externos. Por exemplo: o jogador quer, além de jogar bem, ganhar dinheiro e fama. Mas ele poderia ficar rico e famoso de outras maneiras: exercendo outra profissão, casando-se com uma mulher rica e famosa etc. Assim, certos fins de uma prática só podem ser obtidos mediante determinada prática, e esses são seus fins internos.Os fins internos são, portanto, constitutivos das práticas. Já os fins externos podem ser alcançados de modos diversos.

Pensando a ciência a partir dessa ideia, podemos, a princípio, dizer que seus fins (ou valores) internos dizem respeito à objetividade e à universalidade do conhecimento científico e que os fins (ou valores) externos são, por exemplo, o reconhecimento do cientista, na forma de recompensas materiais ou simbólicas (posição de destaque na comunidade científica). Podemos acrescentar ainda, na categoria de fins externos, os diversos resultados por ela produzidos, como o desenvolvimento de tecnologias, o bem estar, etc. Será, no entanto, o avanço tecnológico possibilitado pela ciência realmente um fim externo a ela? Onde localizar, na categorização de MacIntyre, a tecnologia?

Essa é a questão que desenvolveremos. Já no sec. XVII, Descartes associa conhecimento e técnicas:
A palavra filosofia significa o estudo da sabedoria, e por sabedoria entendemos não só a prudência nos negócios, mas um perfeito conhecimento de todas as coisas que o homem pode saber, tanto para a conduta de sua vida, quanto para a conservação da saúde e a invenção de todas as artes". (Carta do autor ao tradutor dos Princípios de Filosofia - itálico nosso).

Com palavras de seu tempo, o filósofo coloca o projeto tecnológico no cerne da ciência, mas, de algum modo, o localiza em seguida ao conhecimento.

\section{FINS INTERNOS E FINS EXTERNOS À CIÊN- CIA: primeira aproximação}

Antes de enfrentar a pergunta formulada acima, passemos a uma análise mais detida dos fins ou valores internos e externos à ciência. Em sua acepção mais tradicional, a ciência pode ser definida como a busca ou produção do conhecimento. Ora, se a relação com o conhecimento é a característica mais essencial da ciência, então podemos aceitar que a produção do conhecimento objetivo é a sua finalidade específica, e a objetividade, um valor indispensável a essa prática. As regras e normas de funcionamento da atividade científica serão construídas tendo em vista esse fim.

O exemplo abaixo, cuja fonte na internet está perdida, mostra o quanto a objetividade e a verdade são constituintes da prática científica. Comparem-se duas situações: um cientista que frauda os resultados de sua pesquisa e um político que mente para obter votos. Não defendemos que um caso seja moralmente mais grave do que o outro, mas o certo é que, no segundo caso, a mentira não impossibilita a prática política - ao contrário, o grande Maquiavel fala que, às vezes, ela se torna necessária -, enquanto, no primeiro caso, a mentira, na forma da fraude, corrói essencialmente a prática científica. O compromisso com a objetividade é essencial num caso, talvez não em outro.

Assim, alguns valores sempre acompanham a ciência e implicam uma série de normas que devem obrigatoriamente fazer parte dela - e que re- 
centemente foram descritos como "integridade em pesquisa". Interesses pessoais ou de grupo, financeiros ou ideológicos, não devem interferir na busca da verdade. O importante a observar é que a própria comunidade científica trata de construir mecanismos que possibilitam resguardar seus valores internos, como mostrou o caso recente de Marc Hauser. O famoso pesquisador em psicologia evolucionista foi acusado de falsear dados, o que resultou em investigação do ocorrido pela Universidade de Harvard e, inclusive, em afastamento temporário do cientista de seu posto.

Um grande sociólogo da ciência, Robert Merton, num artigo de 1942, assim definiu os princípios diretores da ciência, ou seu ethos próprio: comunalismo (o conhecimento científico deve visto como conhecimento público, compartilhado); universalismo (nenhuma contribuição deve ser excluída por critérios de raça, gênero, nacionalidade ou outro do tipo - a ciência não pode refletir nenhum particularismo - a ciência não tem pátria); desinteresse (a finalidade não pode ser outra senão o próprio conhecimento, a ciência está acima do interesse particular dos cientistas); e organização de maneira cética (não aceita afirmações sem antes submetê-las à prova). Mais recentemente, o físico e sociólogo John Ziman sintetizou os princípios acima com a sigla CUDOS, ${ }^{2}$ defendendo a ideia de que eles definem a forma clássica da chamada "ciência acadêmica”. Tais princípios podem ser remetidos todos a um único fim ou valor: o conhecimento objetivo.

É claro que Merton, ao descrever a ciência ainda na primeira metade do sec. XX, sabia que a realidade vivida poderia não corresponder à sua descrição teórica. Por exemplo, nem sempre o cientista revela a verdade e nem sempre ele é desinteressado - há vaidades e, mais seriamente, há os casos de fraude, mais ou menos famosos. Mas, se o que é condensado na sigla CUDOS não descreve, na prática, a realidade, sem dúvida os cinco

2 Aqui há um jogo de palavras a partir do termo inglês kudos, que significa: "busca de reconhecimento e de respeito por uma realização”. No caso, mais do que honrarias ou aplausos, o cientista quer o reconhecimento de suas descobertas como verdadeiras, independentemente de quaisquer circunstâncias. princípios correspondem à ideia que se tem da ciência, ou seja, ao que se pensa que a ciência deve ser. Para falar em termos weberianos: trata-se de um "tipo ideal", que descreve o que é essencial a essa prática. Ainda, como já vimos, caso esses princípios sejam abandonados de forma sistemática, a própria existência da atividade científica estará comprometida.

Para abordar os fins externos à ciência, é preciso utilizar uma estratégia que pensa a ciência não só em sua dimensão propriamente epistemológica, mas como uma atividade que se insere em um contexto mais amplo. A abordagem desse tópico importante é de competência dos chamados Estudos Sociais das Ciências. Mostraremos, no entanto, que tais fins têm uma dimensão ética, ou, pelo menos, permitem um questionamento ético.

Podemos identificar os fins externos da ciência, na medida em que essa atividade permite ao cientista ganhar reconhecimento e, em alguns casos, fama, dinheiro e poder. Já vimos que esses fins não são constitutivos da ciência. Também o bem estar, a felicidade e o conforto que pretendemos atingir com o progresso da ciência e da técnica poderiam ser vistos como fins extrínsecos, já que: $1^{\circ}$ - bem estar, felicidade e conforto podem ser alcançados por outros meios; $\mathrm{e} 2^{\circ}$ - muita gente duvida que tal progresso, ao fim e ao cabo, de fato, contribua para a felicidade ou o bem estar da humanidade.

\section{O NOVO MODELO DE CIÊNCIA E A FLUIDEZ DAS FRONTEIRAS ENTRE FINS INTERNOSE EXTERNOS}

No entanto, a ciência realiza, como nenhuma outra atividade, o fim de dominação da natureza pela técnica. Deixando de lado a discussão sobre se o progresso da técnica contribui ou não para a felicidade humana - uma questão há muito tempo polêmica, basta lembrar o primeiro Discurso de Rousseau-, perguntamos aqui, apenas, se o desenvolvimento da técnica pode ser considerado um fim externo à ciência ou se, ao contrário, é constitutivo 
dela, ao lado da produção do conhecimento.

Essa questão se torna mais pertinente se considerarmos novamente a análise do já citado sociólogo da ciência, John Ziman. Ao sintetizar o modelo mertoniano de ciência com a sigla CUDOS, ele também levantou a questão: será que esse modelo, que descreve bem o ethos da ciência acadêmica tal como praticada desde sua origem até a consolidação da sociedade industrial, continua valendo para a ciência tal como se mostra a partir do final do século XX? Não é o caso de entrarmos aqui nas importantes diferenciações estabelecidas por Ziman. Gostaríamos, no entanto, de reter sua descrição da forma de ciência que ele chama de pós-acadêmica, redefinida por sua íntima relação com as exigências de uma sociedade globalizada, pós-industrial e de mercado, cuja manifestação mais acabada poderia ser definida por uma nova sigla - PLACE: Proprietário (o conhecimento é privatizado); Local (voltado para a solução e problemas locais e concretos); Autoritário (dirigido por uma autoridade gerencial - o boss); Comissionado (encomendado: a pesquisa não é livre e desinteressada); Especializado (assunto de expert). À figura um tanto solitária e independente do cientista clássico, que podia desenvolver seus conhecimentos com poucos recursos - pensemos, por exemplo, nas descobertas de Pasteur -, segue-se, em nossa época, uma figura e uma experiência coletivas. O desenvolvimento da pesquisa, hoje, não raro envolve uma equipe numerosa, integrando pessoas de vários lugares do planeta, e exige o uso de equipamentos fora do alcance de qualquer cidadão particular. Em consequência, a produção da tecnologia não se separa da atividade de pesquisa: a tecnologia é, não apenas um fim produzido pelo conhecimento, mas o próprio meio de alcançá-lo. Tanto é assim que falamos em tecnociências, amalgamando, numa só realidade, o aspecto teórico e os desdobramentos práticos do conhecimento. Ainda o aspecto utilitário intervém na visão clássica da autonomia da pesquisa e coloca problemas para ela, na medida em que se quer um conhecimento gerador de efeitos.

Ziman não propõe que o ethos da ciência acadêmica tenha sido simplesmente substituído pelo ethos da ciência industrial, mas, sim, afirma que os dois modos de praticar a ciência convivem nos dias de hoje e podem, muitas vezes, entrar em conflito. Tal conflito é vivido por cientistas das mais diferentes áreas, mas não apenas por eles.

Ora, é preciso lembrar que não é nova a ideia de que a ciência é algo útil e deve ter uma aplicação prática. Ela é importante pelo menos desde a origem da ciência moderna, como vimos acima, na citação de Descartes - o qual nunca defendeu que se deve buscar o "conhecimento pelo conhecimento". No entanto, para o modelo tradicional de ciência, a utilidade do conhecimento é uma questão de simples aplicação, um desdobramento do que se passa, bastante autonomamente, na ordem da investigação. Na medida em que hoje, como vimos, o desenvolvimento da pesquisa depende tanto das tecnologias quanto do financiamento pela sociedade, a ciência contemporânea parece ser dirigida pela dimensão prática ou por seus resultados. No caso das tecnociências, o desenvolvimento tecnológico não pode mais ser considerado simplesmente um fim externo a essa prática.

É importante levar em conta ainda que o surgimento das tecnociências tornou o conhecimento científico crucial para a sociedade como um todo. Não precisamos lembrar ao leitor a imensa transformação que a humanidade experimentou, e de maneira intensa, nos últimos 50 anos, como efeito da condução sistemática da investigação das ciências naturais em todos os seus campos. Porque a ciência interfere profundamente na vida social, econômica e política, ela, hoje, tornou-se mais do que nunca um assunto social, econômico e político. Cientistas e pesquisadores ocupam não apenas as páginas dos jornais, mas o imaginário e o dia a dia da sociedade: filmes (Gattaca, Blade Runner), livros de ficção (Solar, de Ian McEwan) ou de não ficção (A vida imortal de Henrietta Lacks, de Revecca Skloot) e até seriados de TV (The Big Bang Theory) têm a ciência ou os cientistas como protagonistas. Todos sabem que os efeitos do desenvolvimento científico são e serão profundamente sentidos. $\mathrm{O}$ aspecto útil ou nocivo desses efeitos tem necessariamente de ser avaliado. Por isso a 
questão da regulamentação da atividade científica tornou-se tão importante - e um ponto tão difícil de ser estabelecido.

Na medida em que o desenvolvimento científico interfere cada vez mais na sociedade, é compreensível que os chamados valores intrínsecos da ciência não sejam mais suficientes para regulá-la. Ou seja, é necessário que a prática científica se inscreva, como prática social, no conjunto de valores compartilhados pela sociedade. Por isso, parece-nos que a tendência atual de uma maior regulação da ciência pela sociedade é uma realidade que não pode ser ignorada e que veio para ficar.

\section{Dois exemplos de regulação}

Os Comitês de Ética em Pesquisa - instituídos obrigatoriamente no Brasil a partir de 1996 são cada vez mais numerosos e podem interferir até mesmo na metodologia de pesquisa, caso os métodos propostos, embora adequados para obter dados importantes, sejam considerados perigosos para o bem estar ou desrespeitem os direitos de pessoas envolvidas nela. Isso significa que, juntamente com o valor do conhecimento e do progresso científico, há também a noção de que o bemestar e, sobretudo, a autonomia das pessoas (o direito de escolha) contam e valem. $\mathrm{O}$ fato de, na história recente da ciência, o consentimento dos sujeitos envolvidos numa pesquisa ter ganhado cada vez maior importância e maior escopo mostra que a prática da ciência e da pesquisa envolve necessariamente múltiplos valores. A discussão sobre o "direito aos tecidos" ${ }^{3}$ retirados, por exemplo, em processos terapêuticos, relaciona-se não propriamente com possíveis riscos ao bem estar da pessoa, mas, sim, e sobretudo, com o direito de o possível doador saber o destino dos tecidos de seu corpo (que tipo pesquisa será feita, quem vai ganhar dinheiro com ela etc.). A regulação dessas práticas no detalhe é uma tarefa difícil e controversa, mas o debate em torno dos problemas mostra

${ }^{3}$ Sobre esse ponto, ver o livro de Rebecca Skloot sobre as células HeLa. que a ciência importa para muita gente, pois tem a ver com valores de vários tipos.

A tão celebrada autonomia do cientista antigo deu lugar ao gerenciamento da pesquisa pelas políticas científicas, que têm como objetivo introduzir critérios de prioridade que reflitam os valores e necessidades de uma dada sociedade - e, nesse sentido, interferem na busca do conhecimento, ao priorizar uma dada pesquisa ao invés de outra. Tal tipo de direcionamento, ou mesmo de intervenção, é cada vez mais justificado na medida em que a ciência hoje, mais do que uma potência de produção de conhecimento, é uma potência de produção de formas de vida. Ademais, as políticas definem prioridades e exigem escolhas. Permanece, é claro, o problema ético de definir o que é ou não é prioritário (já que os recursos não são ilimitados) e o que é ou não é moral em pesquisa (há casos controversos, como a pesquisa com células-tronco).

\section{CONCLUSÃO}

A ciência tornou-se, como tecnociência, dramaticamente útil ou nociva, motivo pelo qual a sociedade, incluindo a comunidade científica, é chamada também a pensar e a participar de seu novo aspecto. Aqui é importante registrar que "utilidade" é um conceito ético, ou seja, não é um dado empírico e muito menos algo que possa ser definido no interior de uma ciência. "A utilidade é um conceito moral. Não pode ser determinada sem referência a objetivos ou a valores humanos mais gerais [...]" (Ziman, 2000, p. 74). O que é ou parece útil a uns pode ser ou parecer nocivo a outros, a exemplo da discussão sobre os transgênicos.

Um ponto de vista consensual ou mais englobante a esse respeito tem de ser construído social e politicamente. Essa nos parece ser, em síntese, uma das tarefas mais importantes para os cientistas hoje: a de defender não só os clássicos valores intrínsecos da ciência, definidores de sua própria prática, mas também de atentar para o lugar vital que a ciência ocupa em nossa sociedade e 
para os seus chamados valores extrínsecos, que, afinal, não são tão extrínsecos assim, fazendo parte de seu modus operandi.

Recebido para publicação em 28 de setembro de 2012 Aceito em 04 de novembro de 2012

\section{REFERÊNCIAS}

LACEY, Hugh. Valores e atividade científica. São Paulo: Editora 34, 2008. v.1, 2010, v.2.

MACINTYRE, Alasdair. Depois da virtude. Trad. Jussara Simões. Bauru,SP: Editora EDUSC, [1981] 2001.

MERTON, Robert King. A ciência e a estrutura social democrática. In: . Sociologia: teoria e estrutura. Trad. Miguel Maillet. São Paulo: Mestre Jou, 1[1942] 1970.

SKLOOT, Rebecca. A vida imortal de Henrietta Lacks. Trad. Ivo Koritowiski. São Paulo: Companhia das Letras, 2011.

ZIMAN, J. M. Real science - what it is and what it means. Cambridge: Cambridge University Press, 2000. 


\section{SCIENCE, ETHICS AND SOCIETY: the regulation of scientific practice}

\section{Telma de Souza Birchal}

In this paper, we wish to show how, in the past decades, the relationship between science and ethics became central in scientific practice. Recent questions challenge the commitment of scientific knowledge with an objective view of things and the promotion of happiness. To reflect on such issues, we borrowed the concept of practice, as outlined by the Scottish moral philosopher Alasdair MacIntyre, so as to understand the relation between the questions properly pertaining to scientific knowledge and those linked with the utility of science. By way of conclusion, we think it relevant to stress a current task of scientists, not only that of defending the classic values intrinsic to science, defining its own practice, but also that of considering the vital place occupied by science in our society, thus calling attention to its extrinsic values, which in fact are part of its modus operandi.

KEY-words: Science. Ethics. MacIntyre. Practice.

\section{SCIENCE, ÉTHIQUE ET SOCIÉTÉ: réglementer la pratique scientifique}

\section{Telma de Souza Birchal}

Dans cette étude, nous nous proposons de montrer comment, au cours des dernières décennies, la relation entre la science et l'éthique est devenue centrale dans la pratique scientifique. Des questions récentes mettent au défi le compromis de la connaissance scientifique d'avoir une vision objective des choses et de viser la promotion du bonheur. Pour examiner ces questions, nous avons emprunté le concept de pratique, tel qu'il est explicité par le philosophe moral écossais Alasdair MacIntyre, afin de comprendre la relation existante entre les questions directement liées à la connaissance scientifique et les questions liées à l'utilité de la science. En conclusion, il nous semble important de mettre en évidence une tâche actuelle qui incombe aux scientifiques, celle de défendre non seulement les valeurs classiques intrinsèques à la science, définissant leur propre pratique, mais aussi d'être attentifs à la place vitale qu'occupe la science dans notre société et à ses valeurs dites extrinsèques qui, en vérité, font partie de leur modus operandi.

Mots-clés: Science. Éthique. MacIntyre. Pratique.

Telma de Souza Birchal - Doutora em Filosofia. Professora Universidade Federal de Minas Gerais. Dedica-se também a temas ligados a ética e a bioética. Fez parte da Diretoria da ANPOF, gestões 2009-2010 e 20112013. Publicações recentes: Régard sur soi, l'esprit qui connaît: figures de la subjectivité chez Montaigne et Descartes. Montaigne Studies: an interdisciplinary forum, v. 25, p. 31-38, 2013; Pais surdos têm o direito de tentar ter filhos surdos? Revista Opinião Filosófica, v. 3, p. 5-13, 2012; A seleção genética de embriões deve ser proibida por ofender os direitos dos portadores de deficiência? Pensando: revista de Filosofia (UFPI), v. 3, p. 100, 2012 (os dois últimos em co-autoria com Lincoln Frias). 
